\title{
Notes on the vocalizations of Saffron-billed Sparrow (Arremon flavirostris)
}

\section{Peter Boesman}

In the following we briefly analyze and compare voice of the three races of Saffron-billed Sparrow (Arremon flavirostris). We also try to quantify the extent of any vocal differences using the criteria proposed by Tobias et al. (2010), as a support for taxonomic review. We have made use of sound recordings available on-line from Xeno Canto (XC).

Song of all races is a short very high-pitched phrase repeated with intervals. A comparison of songs:

\section{Andean group (dorbignii)}

(The following sonograms have a duration of $5 \mathrm{~s}$, frequency starts at $5 \mathrm{kHz}$ )

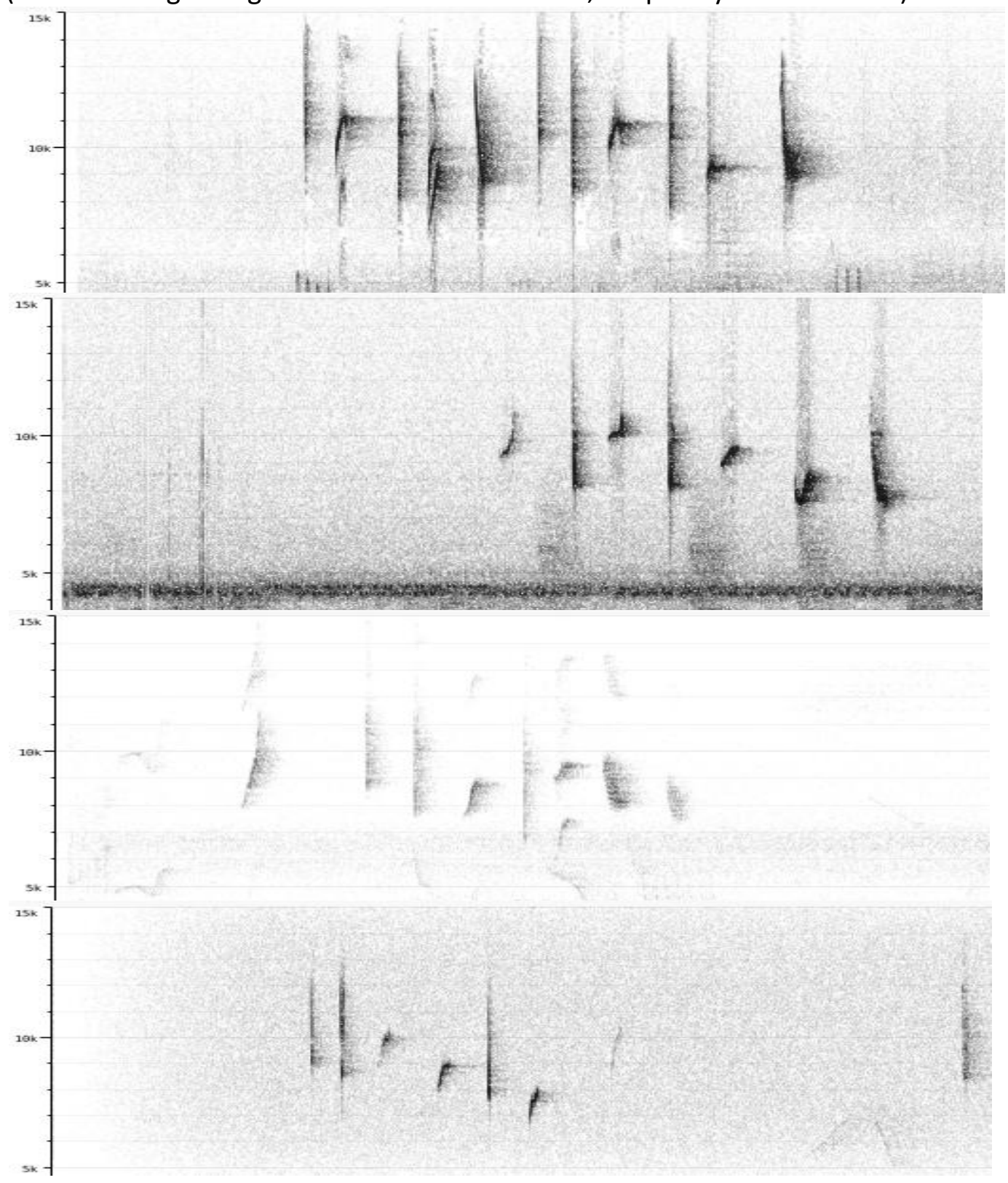




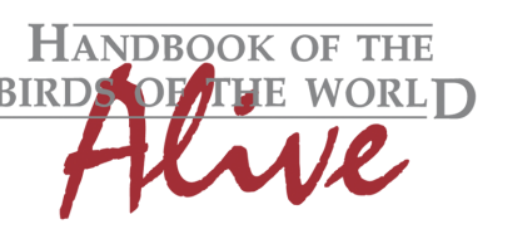

ORNITHOLOGICAL NOTES
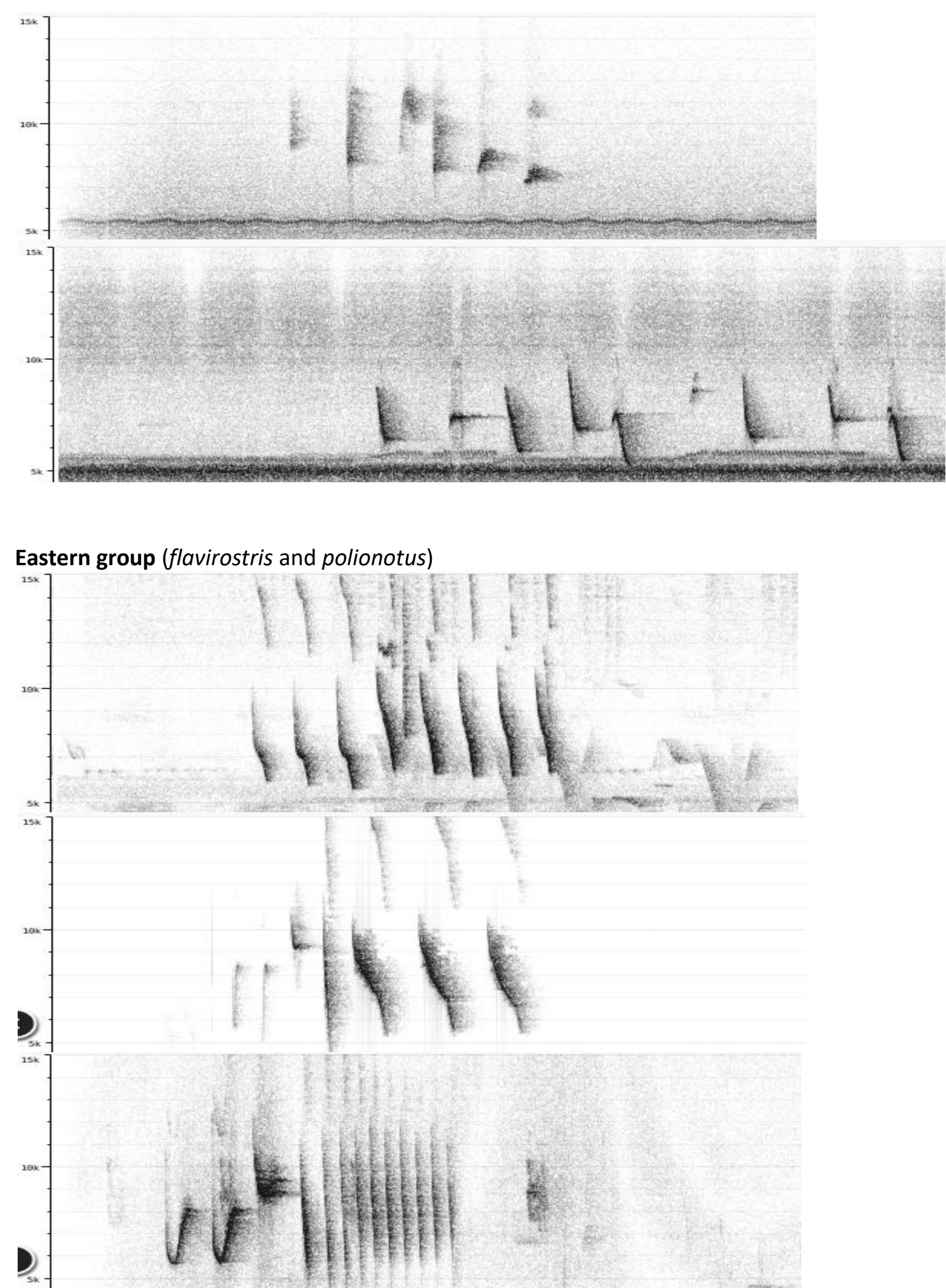

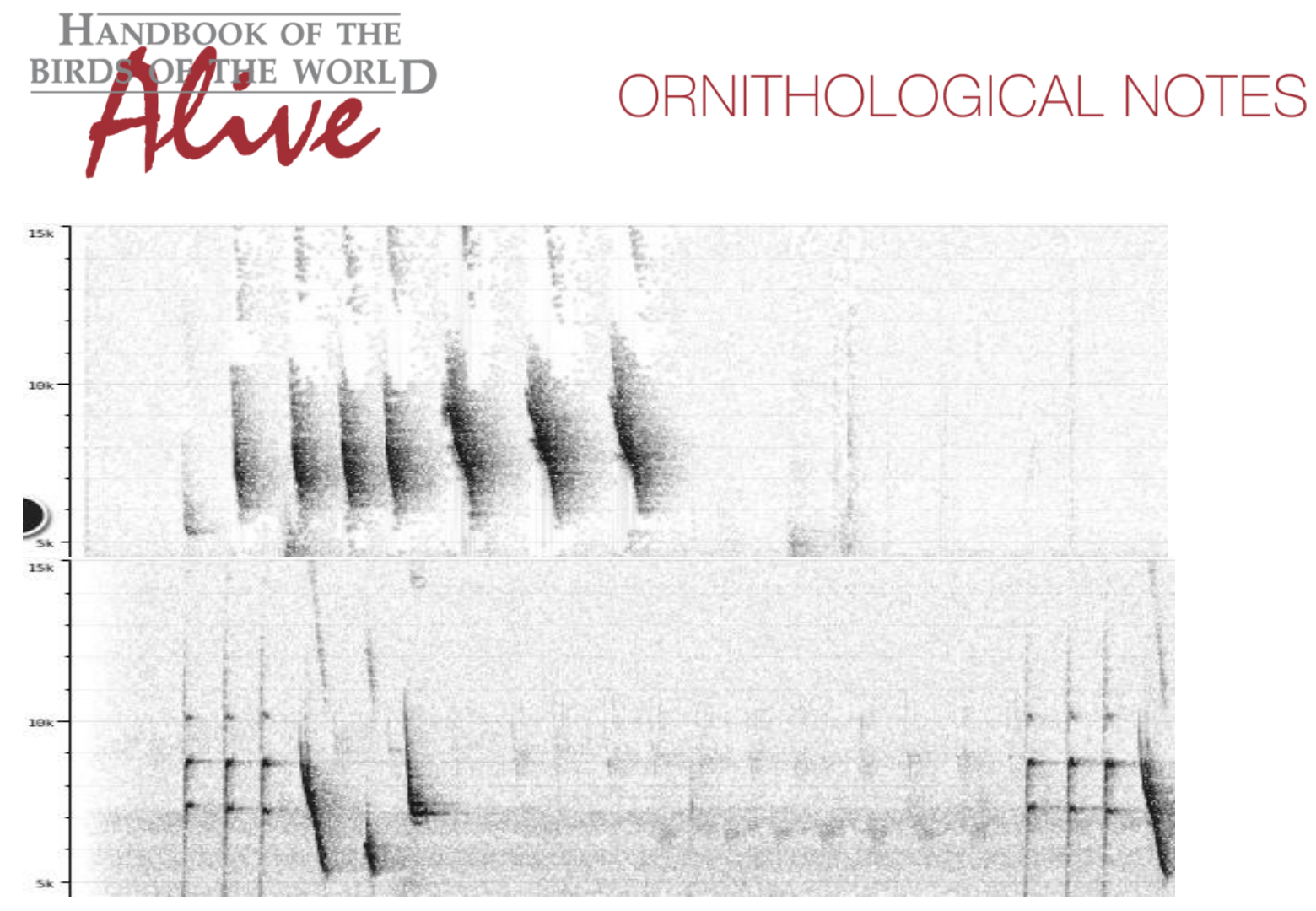

Above examples clearly illustrate vocal differences between Andean birds and the Brazilian taxa:

Andean group has a song phrase in which notes are never repeated in a sequence, and as a matter of fact, few if any notes in the phrase are identical. In all song phrases there are one or more notes with a narrow frequency range of $c 1-1.5 \mathrm{kHz}$ (the last sonogram example of this group is a rather unusual song, but still follows above rule). Almost all notes in a song phrase are above $7 \mathrm{kHz}$ (except for that last example).

In the Brazilian group (green/grey-backed) all song phrases have identical repeated notes in series of usually 3-5. In only few song phrases there are notes with a narrow frequency range, then usually just one. Almost all notes in a song phrase go down to frequencies of $6 \mathrm{kHz}$ or lower (the last example of this group is again a bit less typical, but still shows repeats and lower-pitched notes).

While there are apparently exceptions, there are on average clear vocal differences between the Andean group and the Eastern group: The Andean group typically has no series of identical repeats, min. frequency of notes is higher and number of notes with narrow freq. range is higher. At least the large majority of song phrases can readily be assigned to one of both groups.

Buainain et al. (2016) followed a different approach and identified all clearly different song patterns (a total of 26 patterns was identified in 101 recordings). They conclude that the Andean group has (only) a single song pattern in common with race polionotus and none with nominate. 

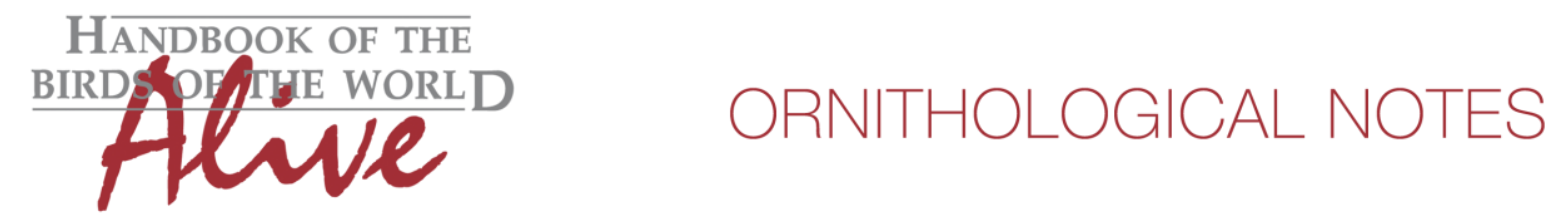

It is likely this very limited overlap in song patterns is due to the following recording: ML193190 (La Paz, Bolivia)

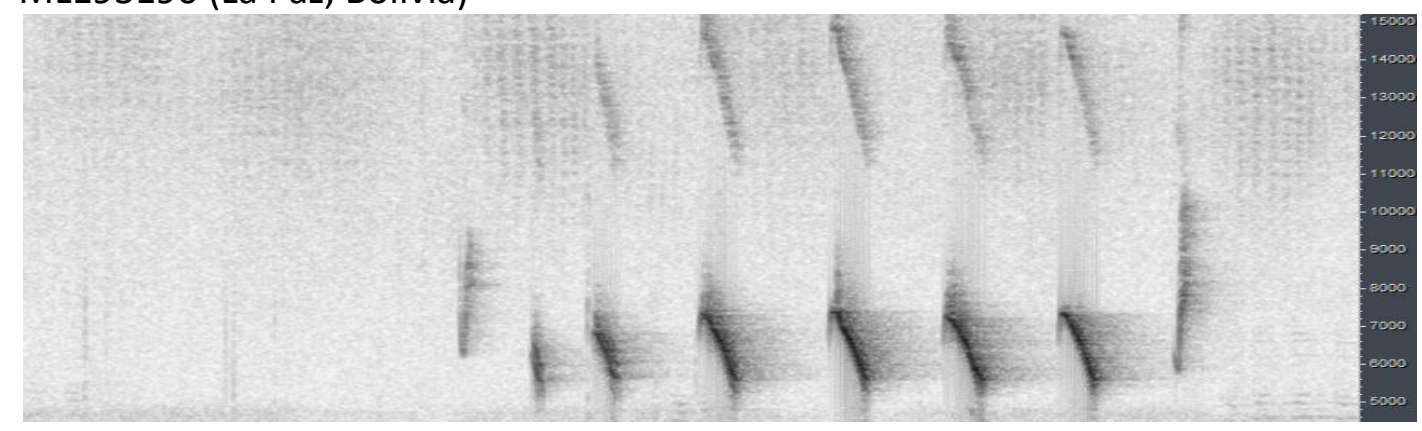

This song phrase indeed shows repeats and is quite low-pitched (although notes have a rather small frequency range and note shape like last example of Andean group (the 'unusual' song).

All in all, we can thus conclude that the Andean group has a distinctive song, although in very few cases difference with Eastern group is very small.

The Andean group has usually no series of identical repeats (1-2), min. frequency of notes is usually higher (1) and number of notes with narrow freq. range is higher (1).

Application of Tobias criteria would lead to a total vocal score of about 3.

This note was finalized on 28th October 2016, using sound recordings available on-line at that moment. We would like to thank in particular the many sound recordists who placed their recordings for this species on XC and ML.

\section{References}

Buainain, N., Brito, G.R.R., Firme, D.H., Figueira, D.M., Raposo, M.A. \& Assis, C.P. (2016). Taxonomic revision of Saffron-billed Sparrow Arremon flavirostris Swainson, 1838 (Aves: Passerellidae) with comments on its holotype and type locality. Zootaxa 4178(4): 547-567.

Tobias, J.A., Seddon, N., Spottiswoode, C.N., Pilgrim, J.D., Fishpool, L.D.C. \& Collar, N.J. (2010). Quantitative criteria for species delimitation. Ibis 152(4): 724-746.

\section{Recommended citation}

Boesman, P. (2016). Notes on the vocalizations of Saffron-billed Sparrow (Arremon flavirostris). HBW Alive Ornithological Note 444. In: Handbook of the Birds of the World Alive. Lynx Edicions, Barcelona. (retrieved from http://www.hbw.com/node/1287376 on 9 December 2016). 